\title{
HNK-1 (human natural killer-1) glyco-epitope is essential for normal spine morphogenesis in developing hippocampal neurons
}

\section{$\operatorname{AUTHOR}(\mathrm{S}):$}

Morita, Ippei; Kakuda, Shinako; Takeuchi, Yusuke; Kawasaki, Toshisuke; Oka, Shogo

\section{CITATION:}

Morita, Ippei ...[et al]. HNK-1 (human natural killer-1) glyco-epitope is essential for normal spine morphogenesis in developing hippocampal neurons. Neuroscience 2009, 164(4): 1685-1694

\section{ISSUE DATE:}

2009-12-29

URL:

http://hdl.handle.net/2433/88221

\section{RIGHT:}

c 2009 IBRO.; この論文は出版社版でありません。引用の際には出版社 版をご確認ご利用ください。; This is not the published version. Please cite only the published version. 


\title{
HNK-1 glyco-epitope is essential for normal spine morphogenesis in developing hippocampal neurons
}

\author{
Ippei Morita $^{{ }^{*}}$, Shinako Kakuda ${ }^{2 *}$, Yusuke Takeuchi ${ }^{2}$, Toshisuke Kawasaki ${ }^{4}$, and Shogo \\ Oka $^{2}$
}

${ }^{1}$ Department of Biological Chemistry, Graduate School of Pharmaceutical Sciences, Kyoto University, Kyoto 606-8501, ${ }^{2}$ Department of Biological Chemistry, Human Health Sciences, Graduate School of Medicine, Kyoto University, Kyoto 606-8507, Japan, ${ }^{3}$ Division of Biological Chemistry and Biologicals, National Institute of Health Sciences, Tokyo 158-8501, Japan, and ${ }^{4}$ Research Center for Glycobiotechnology, Ritsumeikan University, Shiga 525-8577, Japan.

Address for correspondence and proofs: Shogo Oka, Ph.D.,

Department of Biological Chemistry, Human Health Sciences, Graduate School of Medicine, Kyoto University, Kyoto 606-8503, Japan. Tel. \& Fax: +81-75-751-3959; E-mail: shogo@hs.med.kyoto-u.ac.jp

*These two authors equally contributed.

Section editor: Dr. Leszek Kaczmarek 
Abbreviations: HNK-1, human natural killer-1; GlcAT, glucuronyltransferase; HNK-1ST, HNK-1 sulfotransferase; GlcA, glucuronic acid; Gal, galactose; GlcNAc, $N$-acetylglucosamine; GalT, galactosyltransferase; LTP, long-term potentiation; PSD, postsynaptic density; AMPA, a-amino-3-hydroxy-5-methylisoxazolepropionate; GluR, glutamate receptor 


\section{Abstract}

The HNK-1 (Human Natural Killer-1) glyco-epitope possesses a unique structural feature, a sulfated glucuronic acid attached to lactosamine on the non-reducing termini of glycans. The expression of HNK-1 is temporally and spatially regulated by glucuronyltransferase (GlcAT-P) in the brain. Our previous report showed that mice lacking GlcAT-P almost completely lost HNK-1 expression in the brain and exhibited reduced long-term potentiation (LTP) at hippocampal CA1 synapses. GlcAT-P-deficient mice also showed impaired hippocampus-dependent spatial learning. Although HNK-1 plays an essential role in synaptic plasticity and memory formation, it remains unclear how HNK-1 regulates these functions. In this study, we showed that loss of the HNK-1 epitope resulted in an increase of filopodium-like immature spines and a decrease of mushroom-like mature spines in both the early postnatal mouse hippocampus and cultured hippocampal neurons. However, HNK-1 had no influence on spine density or filopodium formation. Immunofluorescence staining revealed that loss of HNK-1 altered the distribution of postsynaptic proteins such as AMPA-type glutamate receptor subunit GluR2 and PSD-95 from spine heads onto dendritic shafts without affecting synapse formation, resulting in an increase of shaft synapses in cultured GlcAT-P-deficient neurons. GluR2, a major HNK-1 carrier glycoprotein in postsynaptic density, has the ability to promote spine morphogenesis. Overexpression of GluR2 promoted spine growth in both wild-type and GlcAT-P-deficient neurons, but the increase in GlcAT-P-deficient neurons was lower than that in wild-type neurons. This is the first evidence that HNK-1 is a key factor for normal dendritic spine maturation and is involved in the distribution of postsynaptic proteins.

Keywords: filopodium, glucuronyltransferase (GlcAT-P), GluR2, shaft synapse, spine maturation 


\section{Introduction}

Glycosylation is one of the major post-translational protein modifications, especially for cell surface and secreted proteins, which play important roles in a variety of cellular functions (Ohtsubo and Marth, 2006). Several of the carbohydrates that are characteristically expressed on glycoproteins in the nervous system regulate synaptic plasticity (Kleene and Schachner, 2004). Among them, HNK-1 is a well-characterized glyco-epitope found in the nervous system (Morita et al., 2008). HNK-1 is highly expressed in the brain during the early postnatal period, when the neural circuit is being actively formed. This epitope is carried by a series of cell adhesion molecules belonging to the immunoglobulin family cell adhesion molecules (NCAM, L1, P0, etc.) and extracellular matrix proteins (tenascin-R, phosphacan, etc.) (Saghatelyan et al., 2000; Liedtke et al., 2001). The HNK-1 glyco-epitope possesses a unique structure comprising a sulfated trisaccharide ( $\mathrm{HSO}_{3}$-3GlcA $\beta 1-3 \mathrm{Gal} \beta 1-4 \mathrm{GlcNAc-}$ ) and is sequentially biosynthesized by one of two glucuronyltransferases (GlcAT-P or GlcAT-S) (Terayama et al., 1997; Seiki et al., 1999) and a sulfotransferase (HNK-1ST) (Bakker et al., 1997). To investigate the biological function of the HNK-1 epitope in vivo, we generated mice deficient in GlcAT-P, which is a major enzyme accounting for the majority of glucuronyltransferase activity in the nervous system (Yamamoto et al., 2002). The GlcAT-P-deficient mice showed an almost complete loss of HNK-1 expression in their brains and exhibited reduced LTP at Schaffer collateral-CA1 synapses along with defects in spatial memory formation. Similarly, HNK-1ST-deficient mice also showed a reduction in LTP and abnormalities in spatial learning tasks (Senn et al., 2002). Recently, mice deficient in $\beta 4$-galactosyltransferase-2 ( $\beta 4 \mathrm{GalT2}$ ), which is involved in Galß1-4GlcNAc synthesis, were shown to exhibit markedly decreased HNK-1 expression as well as learning/memory impairment (Yoshihara et al., 2009). Although these lines of evidences strongly suggest that the HNK-1 epitope is essential for long-lasting changes in synaptic transmission, little is known about how HNK-1 modulates neural function. 
Dendritic spines are highly specialized actin-rich small protrusions on neuronal dendrites and act as receptive sites for excitatory synaptic transmission. The size and number of spines are associated with synaptic plasticity including LTP and long-term depression (LTD), and it is considered that spine morphology is crucial for learning and memory (Segal, 2005). There are several different views on the origin of dendritic spines. One model is that spines initially form as dynamic filopodium-like protrusions and that these structures are then converted directly to mature spines, coincident with the process of postsynaptic specialization (Dailey and Smith, 1996; Ziv and Smith, 1996; Hering and Sheng, 2001). Another model is that dendritic spines arise from synapses located on dendritic shafts (shaft synapse) (Boyer et al., 1998; Fiala et al., 1998).

$\alpha$-Amino-3-hydroxy-5-methylisoxazolepropionate (AMPA) type glutamate receptors mediate most of the fast excitatory synaptic transmission in the mammalian brain and control synaptic strength (Derkach et al., 2007; Isaac et al., 2007). The abundance of postsynaptic AMPA receptors is closely related to the size of dendritic spine heads and synapses, and their distributions regulate long-lasting synaptic changes. AMPA receptors are heterotetrameric complexes composed of various combinations of four subunits (GluR1-4). All subunits have an amino-terminal extracellular domain where 4-6 potential $N$-glycosylation sites are located (Pasternack et al., 2003). Among them, the extracellular domain of GluR2 has the ability to increase spine size and density in hippocampal neurons (Passafaro et al., 2003). The extracellular domain of GluR2 has 4 potential $N$-glycosylation sites, and the HNK-1 glyco-epitope is selectively expressed on the GluR2 subunit (I. Morita et al., unpublished observations).

In the present study, we showed that GlcAT-P-deficient mice had a large number of filopodium-like immature spines on their pyramidal neurons during the early postnatal period. However, filopodium sprouting and spine density were not affected by loss of the HNK-1 
epitope. These observations indicate that HNK-1 plays an important role in the spine maturation process during conversion from filopodia to mature spines in a developmental stage-specific manner. Moreover, loss of HNK-1 also caused clustering of GluR2 and postsynaptic components on dendritic shafts instead of spine heads, indicating that abundant shaft synapses were formed. Our findings suggest that the HNK-1 glyco-epitope modulates the function of GluR2, resulting in normal spine morphogenesis in hippocampal neurons. 


\section{Experimental procedures}

\section{DNA constructs}

The following mammalian expression plasmids were used: Venus (a GFP variant) attached to a membrane-targeted palmitoylation signal of GAP-43 (pCAGGS-GAP-Venus) was kindly provided by Drs. Y. Yoshihara and A. Miyawaki (RIKEN Brain Science Institute) (Matsuno et al., 2006). GAP-Venus was released from pCAGGS-GAP-Venus with EcoRI and cloned into multi-cloning site A of the pIRES vector (Clontech). Then GlcAT-P was released from pEF-BOS-GlcAT-P (Terayama et al., 1997) with NotI and inserted into multi-cloning site B to yield pIRES-GAP-Venus-GlcAT-P. The 3.2-kb XhoI-XbaI GluR2 fragment derived from pKC24 (pBluescript) -GluR2, which was kindly provided by Dr. M. Mishina (Tokyo University) (Sakimura et al., 1990), was cloned into pcDNA3.1/myc-HisB (Invitrogen) to yield the plasmid pcDNA3.1-GluR2.

\section{DiI labeling}

Mouse brains ( $\mathrm{n}=3$ for each genotype) were fixed in 4\% PFA in PBS and sectioned into 100 $\mu m$ slices using a vibratome (Leica Microsystems). DiI crystals (Molecular Probes), a lipophilic tracer, were placed near the cell bodies of hippocampal CA1 pyramidal neurons to retrogradely label their dendrities. After 2 days, DiI diffusion on the pyramidal cell membrane was traced using confocal Z-series images taken at $0.75 \mu \mathrm{m}$ depth intervals with the FLUOVIEW imaging system (OLYMPUS).

\section{Cell cultures and transfection.}

Primary hippocampal cultures were prepared from postnatal day 0 mouse brains. Hippocampi were trypsinized for $10 \mathrm{~min}$ at $37^{\circ} \mathrm{C}$. Dissociated neurons were plated at $1.0 \times 10^{5}$ cells per well (BD BioCoat Poly-D-Lysine Cellware 4-Well CultureSlide (BD Biosciences) coated with 2 
$\mu \mathrm{g} / \mathrm{ml}$ laminin) in Neurobassal medium (Gibco BRL) supplemented with 2\% B-27 (Gibco BRL) and $500 \mu \mathrm{M}$ L-glutamine. Every 7 days, the cultures were fed by replacing half the medium with feeding medium. Hippocampal neurons were transfected using the MBS Mammalian Transfection Kit (Stratagene).

\section{Immunostaining and antibodies.}

Cultured neurons were fixed in ice-cold methanol at $-20^{\circ} \mathrm{C}$ and then washed with PBS. Neurons were incubated with 3\% BSA in PBS containing primary antibodies for $1 \mathrm{~h}$ at room temperature. HNK-1 monoclonal antibody (a hybridoma cell line was purchased from the American Type Culture Collection), anti-GFP (Nacalai Tesque), anti-PSD-95 (Upstate), and anti-Synaptophysin (FabGennix Inc.), anti-MAP-2 (Santa Cruz Biotechnology), and anit-GluR2 N-term antibodies (Zymed) were used. Alexa 448 and 546 secondary antibodies (Molecular Probes) were used for visualization. To label cytoskeletal F-actin, the neurons were fixed for 5 min in acetone at $-20^{\circ} \mathrm{C}$ and then stained with Alexa Fluor 546 Phalloidine (Molecular Probes).

\section{Immunoprecipitation and immunoblot analysis.}

Cultured hippocampal neurons were lysed with 1 volume of $10 \mathrm{mM}$ Tris-HCl (pH7.4) buffer containing 1\% SDS and boiled for 5 minutes, and then 5 volumes of immunoprecipitation buffer (20 mM Tris- $\mathrm{HCl}$ (pH7.4), 2\% Triton X-100, and $0.3 \mathrm{M} \mathrm{NaCl}$ ) and 4 volumes of $\mathrm{H}_{2} \mathrm{O}$ were added to the lysate. To immunoprecipitate the GluR2 subunit, $4 \mu \mathrm{g} / \mathrm{ml}$ anti-GluR2/3 antibody (Upstate) and $20 \mu \mathrm{l}$ of Protein G Sepharose 4 Fast Flow beads (GE Healthcare) were added into the lysate and rotated for $2 \mathrm{~h}$ at $4^{\circ} \mathrm{C}$. Immunoblot analysis was performed using standard protocols.

\section{Image analysis and quantification.}


For the DiI labeling experiments, neurons were chosen randomly from three independent littermate pairs. For the analysis of GFP-transfected neurons, neurons were chosen from 3-5 independent experiments. Morphological analysis was carried out using MetaMorph image analysis software (Molecular Devices). The length and width of the protrusions along dendrites were measured. Spines and filopodia were classified as follows: spines were defined as 0.5-1.5 $\mu \mathrm{m}$ length protrusions with mushroom-like heads, and filopodia were defined as protrusions longer than $1.5 \mu \mathrm{m}$ without spine heads. In the case of GluR2 overexpression experiments, spines were defined as 0.5-2.0 $\mu \mathrm{m}$ length protrusions with mushroom-like heads, and filopodia were defined as protrusions longer than $2.0 \mu \mathrm{m}$ without spine heads because of the unusual large spine heads. The densities of protrusions, spines and filopodia are indicated as their number per $10 \mu \mathrm{m}$ of dendrite.

\section{Statistical analysis.}

The statistical analyses performed are listed in the individual figure legends, and values are expressed as the mean \pm standard error of the mean (SEM). 


\section{Results}

\section{Loss of the HNK-1 glyco-epitope affects the dendritic spine morphology of pyramidal} neurons

The expression of the HNK-1 glyco-epitope is developmentally regulated in the nervous system and peaks between postnatal days 7 (P7) and P14, which corresponds to the period of neural circuit formation. To examine if the loss of the HNK-1 epitope resulted in abnormalities in neuronal structure, the hippocampal neurons of brain slices prepared from wild-type and GlcAT-P-deficient mice at P14 were visualized by Golgi staining. Compared to wild-type, the overall organization and development of the dendritic trees of individual CA1 pyramidal neurons in the hippocampus appeared relatively normal in the GlcAT-P-deficient mice. Close observation showed that thinner brush-like protrusions were found in GlcAT-P-deficient than in wild-type mice slices (Supplementary Fig. 1).

To analyze the neuronal fine structure in GlcAT-P-deficient mice, we prepared hippocampal slices and visualized CA1 pyramidal neurons by DiI labeling. At P14, most pyramidal neurons in wild-type mice possessed mature spines with mushroom-like heads (Fig. $1 \mathrm{~A}$, arrowheads); whereas, the majority of dendritic protrusions were immature filopodium-like spines in GlcAT-P-deficient mice (Fig. 1A, arrows). To quantify the differences in spine morphology, the lengths, widths, and densities of the protrusions were measured. Cumulative frequency plots obtained from three respective littermates revealed that the distribution of the lengths of the protrusions in GlcAT-P-deficient mice showed a significant shift toward longer lengths, and the distribution of the widths shifted toward thinner widths (Fig. 1B). The mean length of GlcAT-P-deficient mice increased to $136.8 \%$ of that of wild-type mice (Fig. 1B, left panel inset, and Table $1,{ }^{*} p<0.05$ ), and the mean width decreased to $87.7 \%$ of that of wild-type (Fig. 1B, right panel inset, and Table $1,{ }^{*} p<0.05$ ). However, the protrusion density was not significantly different between the two groups (Fig. 1C and Table 1, $p=0.59$ ). In addition, we 
classified the protrusions into mature spines and filopodia according to the criteria described in Experimental procedures. As shown in Fig. 1C, $75.6 \pm 2.1 \%$ of dendritic protrusions were mature spines in wild-type mice, but only $43.7 \pm 1.8 \%$ were in GlcAT-P-deficient mice $\left({ }^{*} p<\right.$ $0.01)$.

In adult mice (P70), most of the dendritic protrusions had grown into mature spines in both wild-type and GlcAT-P-deficient mice (Fig. 1D). There were no differences in length (wild-type, $1.05 \pm 0.03 \mu \mathrm{m}$; GlcAT-P -/-, $1.17 \pm 0.01 \mu \mathrm{m}, p=0.49$ ) and width (wild-type, $0.71 \pm$ $0.02 \mu \mathrm{m}$; GlcAT-P -/-, $0.69 \pm 0.02 \mu \mathrm{m}, p=0.58$ ) (Fig. 1E and Table 1). The proportion of mature spines was $83.8 \pm 6.8 \%$ in GlcAT-P-deficient mice, compared to $91.5 \pm 1.0 \%$ in wild-type mice (Fig. 1F and Table 1, $p=0.41$ ). These results suggest that mice lacking HNK-1 exhibit the impairment of spine morphology in the developing brain.

\section{Loss of HNK-1 impairs the maturation of spines in cultured hippocampal neurons}

To address the effect of HNK-1 on spine morphology in detail, we prepared cultured hippocampal neurons. We transfected GFP at 15 days in vitro (DIV) and then visualized spine morphology at 18 DIV. At this stage, wild-type neurons showed robust spine formation, and the immunoreactivity against HNK-1 antibody was diffusely distributed on dendritic shafts and spine heads (Fig. 2A, left, arrowheads). In contrast, GlcAT-P-deficient neurons had many long, thin protrusions extending from dendrites without enlarged spine heads (Fig. 2A, middle). Quantitative analysis showed that the mean length of the protrusions in GlcAT-P-deficient neurons increased to $133.5 \%$ of that in wild-type neurons (Fig. 2B, upper panel inset and Table 2, ${ }^{* *} p<0.01$ ), and the mean width decreased to $75.0 \%$ of that in wild-type neurons (Fig. 2B, lower panel inset, and Table $2,{ }^{* *} p<0.01$ ). However, no significant difference in the protrusion density was observed (Fig. 2C). The proportion of mature spines among all dendritic protrusions was $46.7 \pm 1.3 \%$ and $75.8 \pm 1.5 \%$ in GlcAT-P-deficient and wild-type neurons, respectively (Fig. 
2C, $\left.{ }^{* *} p<0.01\right)$. These data were consistent with the results obtained from hippocampal slices

(Fig. 1), indicating that loss of the HNK-1 epitope also caused significant impairment of spine morphogenesis in cultured hippocampal neurons. On further close observation, we found that the remaining filopodia in GlcAT-P-deficient neurons did not show an irregular appearance. The length was almost always within the range from 1.5 to $3.3 \mu \mathrm{m}$, which is considered to represent normal filopodia in immature neurons $(3.3 \pm 1.1 \mu \mathrm{m})$ (Zhang and Macara, 2006). We hypothesized that loss of HNK-1 leads to inhibition of the conversion of filopodia to mature spines, rather than the sprouting of filopodia. To examine this idea, we examined the morphology of 12 DIV neurons. Wild-type neurons at 12 DIV had elaborated dendrites and filopodia, but did not have mature spines (Fig. 3A). As expected, the quantitative analysis showed that at this time point both wild-type and GlcAT-P-deficient neurons exhibited normal filopodia morphology with mean lengths of $3.23 \pm 0.22 \mu \mathrm{m}$ and $3.20 \pm 0.12 \mu \mathrm{m}$, respectively $(p$ $=0.93$ ), and no significant difference in the density of filopodia (wild-type, $4.14 \pm 0.06$; GlcAT-P -/-, $4.35 \pm 0.27, p=0.51$ ) (Fig. 3B and Table 2). Taken together, these results indicate that loss of HNK-1 results in the inhibition or retardation of spine maturation in cultured hippocampal neurons by affecting the later step(s) of spine morphogenesis (at least after 12 DIV).

\section{Immature spine morphology in GlcAT-P-deficient neurons is rescued by GlcAT-P expression}

To examine whether the altered spine morphology was restored by the re-expression of HNK-1, we co-transfected GFP and GlcAT-P expression plasmids into GlcAT-P-deficient neurons at 15 DIV and then analyzed spine morphology. At 18 DIV (3 days after GlcAT-P transfection), the spine morphology in GlcAT-P-deficient neurons was rescued by GlcAT-P transfection (Fig. 2A, right panel), and HNK-1 staining were also observed on dendritic shafts and spine heads (Fig. 
2A, right panel, arrowheads). The mean length and width of dendritic protrusions reached $97.7 \%$ and $96.4 \%$ of the wild-type values, respectively (Fig. 2B and Table 2). In addition, the proportion of mature spines increased to $78.6 \pm 2.2 \%$, which was comparable to the $75.8 \pm 1.5 \%$ found in wild-type neurons (Fig. 2C and Table 2, $p=0.48$ ). This result indicates that the spine morphology in GlcAT-P-deficient neurons can be mostly restored by HNK-1 expression during the later stage of spine maturation (15 to 18 DIV) in spite of the absence of HNK-1 until 15 DIV.

Loss of the HNK-1 epitope facilitates dendritic accumulation of postsynaptic proteins and shaft synapse formation

Next, to examine whether the absence of HNK-1 had an effect on synapse formation, neurons at 19 DIV were doubly immunostained for PSD-95 (postsynaptic marker protein) and synaptophysin (presynaptic marker protein). In both wild-type and GlcAT-P-deficient neurons, these proteins were clustered and closely apposed to each other, indicating that functional synapses were formed (Fig. 4A). Quantitative analysis revealed that there were no significant differences in the densities of either PSD-95 clusters (Fig. 4B, left) or synapses marked by PSD-95 and synaptophysin clustering (Fig. 4B, right) between wild-type and GlcAT-P-deficient neurons. However, the synapses that formed in GlcAT-P-deficient neurons were localized much more abundantly along dendritic shafts or the dendritic periphery (Fig. 4A, arrows), rather than on spine heads (Fig. 4A, arrowheads). These results indicated that the ability to form synapses was unaffected in GlcAT-P-deficient neurons, but the synapses along dendritic shafts, so-called shaft synapses, were preferentially formed. To investigate the localization of postsynaptic sites in GlcAT-P-deficient neurons, we transfected GFP into hippocampal neurons and immunostained them for PSD-95. Abundant PSD-95 puncta accumulated along dendritic shafts, especially near the bases of the filopodia in GlcAT-P-deficient neurons (Fig. 4C, arrows). 
Recently, we identified the $\alpha$-amino-3-hydroxy-5-methylisoxazolepropionate (AMPA) type glutamate receptor subunit GluR2 as a major HNK-1 carrier protein in postsynaptic density (PSD) and demonstrated that the expression of HNK-1 on GluR2 increases its stability on the cell surface (I. Morita et al., unpublished observations). As shown in Fig. 5A, the HNK-1 epitope was expressed on GluR2 in wild-type neurons but not in GlcAT-P-deficient neurons. To examine if HNK-1 alters the subcellular localization of GluR2, hippocampal neurons at 19 DIV were doubly immunostained for GluR2 and MAP-2 (neurite marker protein). The punctate staining of GluR2 was closely localized along MAP-2 staining (dendritic shafts) in GlcAT-P-deficient neurons compared to that in wild-type (Fig. 4D). Next, we performed double immunostaining for GluR2 and postsynaptic maker proteins, (PSD-95, Fig. 4E) and (F-actin, Fig. 4F). The staining of GluR2 was co-localized with PSD-95 or F-actin at postsynaptic sites, but the clusters of these proteins were also localized on dendritic shafts in GlcAT-P-deficient neurons (Fig. 4E and F, arrowheads). To verify these findings, we measured the fluorescence intensities of GluR2 along a line drawn across the dendrites as shown in Fig. 4F. Wild-type neurons showed two separate intensity peaks of GluR2 corresponding to the localization of dendritic spines (Fig. 4G, upper panel). On the other hand, the GluR2 in GlcAT-P-deficient neurons showed a higher intensity in the dendritic shafts and a less specific localization at dendritic spines (Fig. 4G, lower panel). Taken together, loss of HNK-1 did not inhibit functional synapse formation, but excessive numbers of shaft synapses were formed along dendritic shafts, suggesting that the HNK-1 epitope is necessary for the localization of postsynaptic components including GluR2.

\section{HNK-1 epitope on GluR2 is important for spine morphogenesis}

Recent studies have demonstrated that the extracellular N-terminal domain of GluR2 induces spine morphogenesis and that the spine promoting activity of GluR2 is dependent on its 
interaction with the neural adhesion molecule N-cadherin (Passafaro et al., 2003; Saglietti et al., 2007). Whereas GluR2 were equivalently expressed in wild-type and GlcAT-P-deficient neurons, GluR2 in wild-type neurons carries the HNK-1 epitope but that in GlcAT-P-deficient neurons does not (Fig 5A). We also found that the HNK-1 on GluR2 significantly enhances its interaction with N-cadherin in mouse hippocampus and HEK 293 cells (I. Morita et al., unpublished observations). These results prompted us to examine the possibility that the HNK-1 epitope on GluR2 contributes to spine maturation. So, we co-transfected GFP and GluR2 into wild-type and GlcAT-P-deficient neurons at 13 DIV, before performing analysis at 18 DIV to examine the spine-promoting activity of GluR2. In wild-type neurons, overexpression of GluR2 caused increases in spine length $\left(1.28 \pm 0.01\right.$ to $\left.1.43 \pm 0.03 \mu \mathrm{m},{ }^{* *} p<0.01\right)$ and spine width $\left(0.84 \pm 0.01\right.$ to $\left.1.04 \pm 0.01 \mu \mathrm{m},{ }^{* *} p<0.01\right)$ (Fig. 5B, C and Table 2), which is consistent with the finding of a previous report (Passafaro et al., 2003; Saglietti et al., 2007). On the other hand, in GlcAT-P-deficient neurons, the length of protrusions was decreased $(1.71 \pm 0.02$ to $1.18 \pm$ $0.03 \mu \mathrm{m},{ }^{* *} p<0.01$ ) (Fig. 5B, C and Table 2), due to enhancement of the conversion of filopodia into spines. The spine head width was increased $\left(0.63 \pm 0.01\right.$ to $0.78 \pm 0.02 \mu \mathrm{m},{ }^{* *} p<$ 0.01, Fig. 5B, C and Table 2). Thus, although GluR2 lacking HNK-1 also promotes spine growth, the size (length and width) of the spines in GluR2-overexpressing GlcAT-P-deficient neurons was comparable to that in wild-type neurons but not to that in GluR2-overexpressing wild-type neurons (Table 2). In addition, the spine density was significantly increased by GluR2 overexpression in wild-type neurons $\left(6.23 \pm 0.11\right.$ to $7.32 \pm 0.19$, $\left.{ }^{* *} p<0.01\right)$; whereas, it remained unchanged in GlcAT-P-deficient neurons $(6.72 \pm 0.04$ to $6.50 \pm 0.21, p=0.28)$. Therefore, the ability of GluR2 to induce spine formation in GlcAT-P-deficient neurons was not as effective as that in wild-type neurons, suggesting that the HNK-1 expressed on GluR2 is important for spine maturation. 


\section{Discussion}

The HNK-1 glyco-epitope is widely expressed on some cell adhesion molecules (NCAM, L1, and MAG etc.) and extracellular matrix molecules (tenascin-R and phosphacan etc.) in the nervous system (Morita et al., 2008). It has been reported that HNK-1 mediates the interaction of these adhesion molecules, thereby controlling their functions including cell-to-cell adhesion (Kunemund et al., 1988), migration (Bronner-Fraser, 1987), and neurite extension (Martini et al., 1992). In this study, we first demonstrated the involvement of the HNK-1 epitope in normal spine development of hippocampal neurons. Around postnatal 14 days, neural circuits are actively formed, and the HNK-1 epitope shows the highest expression in the mouse brain. At P14, GlcAT-P-deficient CA1 pyramidal neurons showed more immature filopodium-like protrusions than wild-type neurons (Fig. 1A-C). In adult (P70) mice, GlcAT-P-deficient CA1 pyramidal neurons exhibited normal mature mushroom-like spine structures, and there were no significant differences in length and width between wild-type and GlcAT-P-deficient neurons (Fig. 1D-F). The immature filopodium-like protrusions were also observed in GlcAT-P-deficient cultured neurons at 18 DIV (Fig. 2). These morphological impairments were rescued by the expression of GlcAT-P at 15-18 DIV (Fig. 2). However, the overexpression of GlcAT-P had no effect on spine morphology in wild-type neurons (data not shown), indicating that HNK-1 did not promote spines with irregular sizes and shapes. These observations indicate that the HNK-1 epitope specifically influences normal spine maturation in developing brains and that its influence gradually decreases during the course of postnatal development.

As the HNK-1 epitope is almost completely absent fron GlcAT-P-deficient mice (Yamamoto et al., 2002), it is very difficult to demonstrate which HNK-1 carrier protein is responsible for normal spine formation. We focused on the HNK-1 on the AMPA-type glutamate receptor subunit GluR2 for the following reasons. First, we identified GluR2 as a major HNK-1 carrier at postsynaptic sites (I. Morita et al., unpublished data). GluR2 localizes 
in PSD and is a key molecule in long-term synaptic changes and dendritic spine morphogenesis (Isaac et al., 2007). We also showed that the HNK-1 epitope on GluR2 increased its interaction with N-cadherin and the expression of GluR2 on the neural surface membrane (I. Morita et al., unpublished data). This interaction is necessary for the promotion of the enlargement of dendritic spines (Saglietti et al., 2007). Second, in GlcAT-P-deficient neurons, GluR2 and PSD proteins were localized on the shafts of dendrites, and abundant shaft synapses were formed (Fig. 4). It was reported that Rap2, a member of the Rap family of small GTPases, regulated the distribution of GluR2 and AMPA receptor-mediated mEPSC (Fu et al., 2007). Furthermore, the active form of Rap2 caused a reduction in surface GluR2 levels, the loss of dendritic spines, and an increase in filopodium-like protrusions and shaft synapses (Fu et al., 2007). These results are consistent with the phenomena observed in GlcAT-P-deficient neurons (Fig. 4), suggesting that the abnormalities in GlcAT-P-deficient neurons are modulated by reduction of the surface GluR2 level. Third, in a rescue experiment, the transfection of GlcAT-P completely restored spine immaturity in 15 to 18 DIV neurons (Fig. 2). This corresponds well to the time window (15 to 18 DIV) during which GluR2 plays an important role in spine maturation by being translocated from dendritic shafts to forming spine heads (Pickard et al., 2000). Finally, when GluR2 was overexpressed in GlcAT-P-deficient neurons, the maturation of the dendritic spines was not promoted as effectively as in wild-type neurons, indicating that overexpressed GluR2 does not function fully in the absence of the HNK-1 epitope (Fig. 5). These lines of evidence strongly support the notion that GluR2 and HNK-1 modulate spinogenesis in the hippocampus. Although we can not exclude the possibility that other HNK-1 carrier glycoproteins are involved in spine maturation, HNK-1 on GluR2 must be one of the most critical factors.

We found that excessive numbers of shaft synapses were present in mature GlcAT-P-deficient neurons compared with wild-type neurons (Fig. 4). In general, shaft synapses are considered as precursors of dendritic spine synapses during development and 
activity-dependent synaptogenesis (Fiala et al., 1998; Ethell and Pasquale, 2005). In young brains, glutamatergic neurons have abundant shaft synapses on their dendrites, and the number of shaft synapses decreases with increase in the number of dendritic spines during brain development (Boyer et al., 1998). On the other hand, recent studies have argued that shaft synapses may have roles other than being the precursor of spine synapses. It was reported that the numbers of shaft and spine synapses are independently regulated by behavioral learning and the induction of synaptic plasticity (Helmeke et al., 2001; Zha et al., 2005; Nikolakopoulou et al., 2006), suggesting that distinct mechanisms are involved in regulation of these two types of synapses. Although it was recently reported that the expression of EphrinB3 and the inhibition of CaMKII promoted shaft synapse formation (Aoto et al., 2007; Zha et al., 2009), the detailed molecular mechanisms behind shaft synapse formation remain unclear. GlcAT-P-deficient mice may provide a good model for understanding the formation of shaft synapses and shaft synapse-related synaptic functions.

As for synaptic plasticity, the HNK-1 epitope carried by tenascin-R has been well characterized. Tenascin- $\mathrm{R}$ is abundant in the perineuronal nets surrounding parvalbmin-positive interneurons (Wintergerst et al., 1996; Bruckner et al., 2000). It is proposed that the HNK-1 on tenascin-R reduces GABA release for the perisomatic inhibition of CA1 pyramidal neurons, resulting in the reduction of LTP in CA1 pyramidal neurons (Saghatelyan et al., 2000; Dityatev and Schachner, 2003). Recently, Bukalo et al demonstrated that the reduction of LTP in tenascin-R-deficient mice is due to increased threshold for induction of LTP, and the peptidomimetic of HNK-1 carbohydrate restored the impaired LTP in tenascin-R-deficient mice, indicating that HNK-1 carried by tenascin-R is important for synaptic plasticity (Bukalo et al., 2007). In this study, we showed that HNK-1 was associated with the morphology of dendritic spines as well as the distribution of AMPA receptors. The impairment of spine maturation in GlcAT-P-deficient mice was gradually reversed during the course of postnatal development in 
vivo. The relationship between impaired spine maturation in developing brains and reduced LTP in adult brains of GlcAT-P-deficient mice remains unclear. It is possible that after the induction of plastic changes at synapses in adult mice, structural differences of spines between wild-type and GlcAT-P-deficient mice becomes evident. While further investigation is necessary to elucidate the overall role of the HNK-1 carbohydrate in synaptic plasticity, our current results suggest that the HNK-1 carried by GluR2 contributes to structural plasticity of dendritic spines. 


\section{Acknowledgements}

We would like to thank Drs. A. Ikeda (Kyoto Univ.), T. Seki (Juntendo Univ.), and Y. Yoshihara (RIKEN) for valuable discussions and technical advice. This work was supported in part by a Grant-in-Aid for Scientific Research (B) 21370053 (to S. O) from the Ministry of Education, Culture, Sports, Science and Technology, and by the Mizutani Foundation for Glycoscience (to S. O). 


\section{References}

Aoto J, Ting P, Maghsoodi B, Xu N, Henkemeyer M, Chen L (2007) Postsynaptic ephrinB3 promotes shaft glutamatergic synapse formation. J Neurosci 27:7508-7519.

Bakker H, Friedmann I, Oka S, Kawasaki T, Nifant'ev N, Schachner M, Mantei N (1997) Expression cloning of a cDNA encoding a sulfotransferase involved in the biosynthesis of the HNK-1 carbohydrate epitope. J Biol Chem 272:29942-29946.

Bukalo O, Schachner M, Dityatev A (2007) Hippocampal metaplasticity induced by deficiency in the extracellular matrix glycoprotein tenascin-R. J Neurosci 27:6019-6028.

Boyer C, Schikorski T, Stevens CF (1998) Comparison of hippocampal dendritic spines in culture and in brain. J Neurosci 18:5294-5300.

Bronner-Fraser M (1987) Perturbation of cranial neural crest migration by the HNK-1 antibody. Dev Biol 123:321-331.

Dailey ME, Smith SJ (1996) The dynamics of dendritic structure in developing hippocampal slices. J Neurosci 16:2983-2994.

Derkach VA, Oh MC, Guire ES, Soderling TR (2007) Regulatory mechanisms of AMPA receptors in synaptic plasticity. Nat Rev Neurosci 8:101-113.

Ethell IM, Pasquale EB (2005) Molecular mechanisms of dendritic spine development and remodeling. Prog Neurobiol 75:161-205.

Fiala JC, Feinberg M, Popov V, Harris KM (1998) Synaptogenesis via dendritic filopodia in developing hippocampal area CA1. J Neurosci 18:8900-8911.

Fu Z, Lee SH, Simonetta A, Hansen J, Sheng M, Pak DT (2007) Differential roles of Rap1 and Rap2 small GTPases in neurite retraction and synapse elimination in hippocampal spiny neurons. J Neurochem 100:118-131.

Helmeke C, Ovtscharoff W, Jr., Poeggel G, Braun K (2001) Juvenile emotional experience alters synaptic inputs on pyramidal neurons in the anterior cingulate cortex. Cereb Cortex 
11:717-727.

Hering H, Sheng M (2001) Dendritic spines: structure, dynamics and regulation. Nat Rev Neurosci 2:880-888.

Isaac JT, Ashby M, McBain CJ (2007) The role of the GluR2 subunit in AMPA receptor function and synaptic plasticity. Neuron 54:859-871.

Kleene R, Schachner M (2004) Glycans and neural cell interactions. Nat Rev Neurosci 5:195-208.

Kunemund V, Jungalwala FB, Fischer G, Chou DK, Keilhauer G, Schachner M (1988) The L2/HNK-1 carbohydrate of neural cell adhesion molecules is involved in cell interactions. J Cell Biol 106:213-223.

Liedtke S, Geyer H, Wuhrer M, Geyer R, Frank G, Gerardy-Schahn R, Zahringer U, Schachner M (2001) Characterization of N-glycans from mouse brain neural cell adhesion molecule. Glycobiology 11:373-384.

Martini R, Xin Y, Schmitz B, Schachner M (1992) The L2/HNK-1 Carbohydrate Epitope is Involved in the Preferential Outgrowth of Motor Neurons on Ventral Roots and Motor Nerves. Eur J Neurosci 4:628-639.

Matsuno H, Okabe S, Mishina M, Yanagida T, Mori K, Yoshihara Y (2006) Telencephalin slows spine maturation. J Neurosci 26:1776-1786.

Morita I, Kizuka Y, Kakuda S, Oka S (2008) Expression and function of the HNK-1 carbohydrate. J Biochem 143:719-724.

Nikolakopoulou AM, Davies HA, Stewart MG (2006) Passive avoidance training decreases synapse density in the hippocampus of the domestic chick. Eur J Neurosci 23:1054-1062.

Ohtsubo K, Marth JD (2006) Glycosylation in cellular mechanisms of health and disease. Cell 126:855-867. 
Passafaro M, Nakagawa T, Sala C, Sheng M (2003) Induction of dendritic spines by an extracellular domain of AMPA receptor subunit GluR2. Nature 424:677-681.

Pasternack A, Coleman SK, Fethiere J, Madden DR, LeCaer JP, Rossier J, Pasternack M, Keinanen K (2003) Characterization of the functional role of the N-glycans in the AMPA receptor ligand-binding domain. J Neurochem 84:1184-1192.

Pickard L, Noel J, Henley JM, Collingridge GL, Molnar E (2000) Developmental changes in synaptic AMPA and NMDA receptor distribution and AMPA receptor subunit composition in living hippocampal neurons. J Neurosci 20:7922-7931.

Saghatelyan AK, Gorissen S, Albert M, Hertlein B, Schachner M, Dityatev A (2000) The extracellular matrix molecule tenascin-R and its HNK-1 carbohydrate modulate perisomatic inhibition and long-term potentiation in the CA1 region of the hippocampus. Eur J Neurosci 12:3331-3342.

Saglietti L, Dequidt C, Kamieniarz K, Rousset MC, Valnegri P, Thoumine O, Beretta F, Fagni L, Choquet D, Sala C, Sheng M, Passafaro M (2007) Extracellular interactions between GluR2 and N-cadherin in spine regulation. Neuron 54:461-477.

Sakimura K, Bujo H, Kushiya E, Araki K, Yamazaki M, Yamazaki M, Meguro H, Warashina A, Numa S, Mishina M (1990) Functional expression from cloned cDNAs of glutamate receptor species responsive to kainate and quisqualate. FEBS Lett 272:73-80.

Segal M (2005) Dendritic spines and long-term plasticity. Nat Rev Neurosci 6:277-284.

Seiki T, Oka S, Terayama K, Imiya K, Kawasaki T (1999) Molecular cloning and expression of a second glucuronyltransferase involved in the biosynthesis of the HNK-1 carbohydrate epitope. Biochem Biophys Res Commun 255:182-187.

Senn C, Kutsche M, Saghatelyan A, Bosl MR, Lohler J, Bartsch U, Morellini F, Schachner M (2002) Mice deficient for the HNK-1 sulfotransferase show alterations in synaptic efficacy and spatial learning and memory. Mol Cell Neurosci 20:712-729. 
Terayama K, Oka S, Seiki T, Miki Y, Nakamura A, Kozutsumi Y, Takio K, Kawasaki T (1997) Cloning and functional expression of a novel glucuronyltransferase involved in the biosynthesis of the carbohydrate epitope HNK-1. Proc Natl Acad Sci U S A 94:6093-6098.

Yamamoto S, Oka S, Inoue M, Shimuta M, Manabe T, Takahashi H, Miyamoto M, Asano M, Sakagami J, Sudo K, Iwakura Y, Ono K, Kawasaki T (2002) Mice deficient in nervous system-specific carbohydrate epitope HNK-1 exhibit impaired synaptic plasticity and spatial learning. J Biol Chem 277:27227-27231.

Yoshihara T, Sugihara K, Kizuka Y, Oka S, Asano M (2009) Learning/memory impairment and reduced expression of the HNK-1 carbohydrate in beta 4-galactosyltransferase-II-deficient mice. J Biol Chem.

Zha XM, Dailey ME, Green SH (2009) Role of Ca2+/calmodulin-dependent protein kinase II in dendritic spine remodeling during epileptiform activity in vitro. J Neurosci Res 87:1969-1979.

Zha XM, Green SH, Dailey ME (2005) Regulation of hippocampal synapse remodeling by epileptiform activity. Mol Cell Neurosci 29:494-506.

Zhang H, Macara IG (2006) The polarity protein PAR-3 and TIAM1 cooperate in dendritic spine morphogenesis. Nat Cell Biol 8:227-237.

Ziv NE, Smith SJ (1996) Evidence for a role of dendritic filopodia in synaptogenesis and spine formation. Neuron 17:91-102. 


\section{Figure legends}

Fig. 1 Impaired spine morphology of pyramidal neurons in GlcAT-P-deficient (GlcAT-P -/-) hippocampal slices. (A) Representative images of DiI-labeled apical dendrites of CA1 pyramidal neurons in hippocampal slices from P14 wild-type and GlcAT-P -/- mice. Arrowheads indicate dendritic spines, and arrows indicate filopodia. Scale bars: $10 \mu \mathrm{m}$ in the upper panel and $1 \mu \mathrm{m}$ in the lower panel. (B) Cumulative frequency plots of the length and width of dendritic protrusions $(\mathrm{n}=1,090$ protrusions for wild-type neurons; $\mathrm{n}=1,147$ protrusions for GlcAT-P -/- neurons). $p<0.01$ (Kolmogorov-Smirnov test). Inset histograms show mean values ( $n=3$, 276-498 protrusions per experiment for wild-type neurons; $n=3$, 247-465 protrusions per experiment for GlcAT-P $-/-$ neurons). ${ }^{*} p<0.05$ (two-tailed $t$ test). (C) The densities of protrusions in (B) ( $n=3,13-15$ cells per experiment for wild-type neurons; $n=3$, 13-17 cells per experiment for GlcAT-P -/- neurons). The numbers on the bars indicate the percentages of mature mushroom-like spines within all protrusions. ${ }^{* *} p<0.01$ (two-tailed $t$ test). (D) Representative images of DiI-labeled apical dendrites of CA1 pyramidal neurons in hippocampal slices from P70 wild-type and GlcAT-P -/- mice. (E) Cumulative frequency plots of the length and width of dendritic protrusions at P70 $(n=927$ protrusions for wild-type neurons; and $n=970$ protrusions for GlcAT-P -/- neurons). Inset histograms show mean values ( $\mathrm{n}=3$, 294-450 protrusions per experiment for wild-type neurons; and $n=3$, 235-388 protrusions per experiment for GlcAT-P -/- neurons). (F) The densities of protrusions in (E) (n = 3, 8-9 cells per experiment for wild-type neurons; $n=3$, 8-10 cells per experiment for GlcAT-P -/- neurons). Error bars indicate SEM.

Fig. 2 Impaired spine morphology of cultured GlcAT-P -/- hippocampal neurons. (A) Cultured hippocampal neurons were transfected with GFP alone (left and middle) or GFP plus GlcAT-P (right) at 15 DIV and were then double immunostained for GFP (green) and HNK-1 (red) at 18 
DIV. Higher magnification panels show individual dendrite segments. Arrowheads indicate HNK-1 staining on the dendritic spines. Scale bars: $50 \mu \mathrm{m}$ in the upper panel and $5 \mu \mathrm{m}$ in the lower panel. (B) Cumulative frequency plots of the length and width of protrusions ( $n=916$ for wild-type neurons; $n$ = 933 for GlcAT-P -/- neurons; n = 923 for GlcAT-P -/- neurons rescued with GlcAT-P). $p<0.01$ (Kolmogorov-Smirnov test). Inset histograms show mean values $(\mathrm{n}=4$, 197-231 protrusions per experiment for wild-type neurons; $n=4$, 189-216 protrusions per experiment for GlcAT-P -/- neurons; $\mathrm{n}$ = 5, 153-196 protrusions per experiment for GlcAT-P -/neurons rescued with GlcAT-P). ${ }^{*} p<0.05,{ }^{* *} p<0.01$ (two-tailed $t$ test). (C) The densities of protrusions in (B) ( $n=4$, 9-10 cells per experiment for wild-type neurons; $n=4$, 9-10 cells per experiment for GlcAT-P -/- neurons; $n$ = 5, 6-10 cells per experiment for GlcAT-P -/- neurons rescued with GlcAT-P). The numbers on the bars indicate the percentages of mature spines within all protrusions. ${ }^{* *} p<0.01$ (two-tailed $t$ test). Error bars indicate SEM.

Fig. 3 Normal morphology of filopodia in GlcAT-P -/- neurons. (A) Cultured hippocampal neurons were transfected with GFP at 10 DIV and then immunostained for GFP at 12 DIV. Individual dendrite segments from wild-type and GlcAT-P -/- neurons are presented. Scale bar: $10 \mu \mathrm{m}$. (B) Quantification of mean length and filopodia density as in (A) ( $\mathrm{n}=3$, 3-4 cells and 66-94 filopodia per experiment for wild-type neurons; $\mathrm{n}=3$, 3-4 cells and 59-108 filopodia per experiment for GlcAT-P -/- neurons). Histograms show the mean length (left) and the mean density of filopodia (right) of wild-type and GlcAT-P -/- neurons. Error bars indicate SEM.

Fig. 4 Effects of HNK-1 on the formation and localization of synapses. (A) Double immunostaining for PSD-95 (green) and synaptophysin (red) in cultured hippocampal neurons at 19 DIV. Arrowheads indicate dendritic synapses in wild-type neurons, and arrows indicate the shaft synapses in GlcAT-P -/- neurons. Note that the PSD-95 puncta on dendritic shafts were 
also apposed to synaptophysin, indicating the formation of synapses in GlcAT-P -/- neurons. (B) Quantification of the densities of PSD-95 clusters and synapses on dendrites in (A). Histograms show the number of PSD-95 clusters (left) and synapses (right) per $10 \mu \mathrm{m}$ dendrite. (C) Cultured hippocampal neurons were transfected at 15 DIV with GFP and were then double immunostained for GFP (green) and PSD-95 (red) at 18 DIV. Arrowheads indicate clusters of PSD-95 on spine heads in wild-type neurons, and arrows indicate PSD-95 on dendritic shafts near the bases of filopodia in GlcAT-P -/- neurons. (D) Double immunostaining for GluR2 (green) and MAP-2 (red) in cultured hippocampal neurons at 19 DIV. Arrowheads indicate GluR2 puncta on dendritic spine heads in wild-type neurons, and arrows indicate GluR2 accumulated on dendritic shafts in GlcAT-P -/- neurons. (E) Double immunostaining for GluR2 (green) and PSD-95 (red) in cultured hippocampal neurons at 19 DIV. Arrowheads and arrows indicate the same as in (D). (F) Double immunostaining for GluR2 (green) and F-actin (red) in cultured hippocampal neurons at 19 DIV. Arrowheads and arrows indicate the same as in (D). (G) GluR2 in GlcAT-P -/- neurons showed excessive accumulation on dendritic shafts. For the determination of the localization of GluR2, lines were drawn across the dendrites (yellow lines in (F)), and the fluorescence intensity profiles of GluR2 along the lines were obtained.

Fig. 5 HNK-1 epitope on GluR2 is crucial for spine morphology. (A) GluR2 was immunoprecipitated from cultured hippocampal neurons. GluR2 in GlcAT-P -/- neurons showed no HNK-1 expression. (B) Representative images of individual dendrite segments of GluR2-overexpressing neurons. Wild-type and GlcAT-P -/- neurons were transfected with GFP and GluR2 at 13 DIV and immunostained for GFP at 18 DIV. Scale bars: $5 \mu \mathrm{m}$. (C) Cumulative frequency plots of the spine length and width of dendritic protrusions ( $n=565$ for wild-type neurons; $\mathrm{n}=519$ for GlcAT-P -/- neurons). $p<0.01$ (Kolmogorov-Smirnov test). Inset histograms show mean values $(n=3,150-232$ protrusions per experiment for wild-type 
neurons; $\mathrm{n}=3$, 141-203 protrusions per experiment for GlcAT-P -/- neurons). ${ }^{*} p<0.05$, ${ }^{* *} p<$ 0.01 (two-tailed $t$ test). (D) The protrusion densities in (C) $(n=3,4-5$ cells per experiment for wild-type neurons; $\mathrm{n}=3$, 5-6 cells per experiment for GlcAT-P -/- neurons). ${ }^{*} p<0.05$ (two-tailed $t$ test). 
Fig. 1

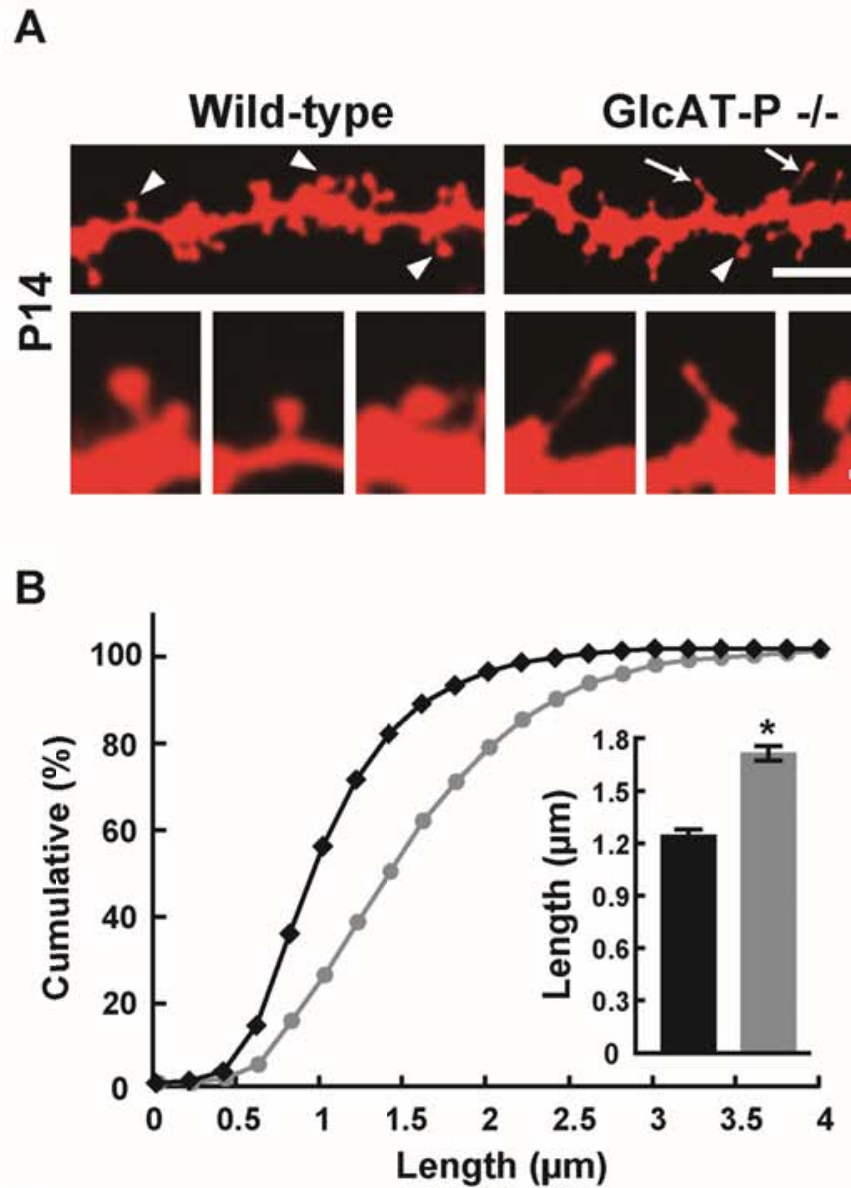

D

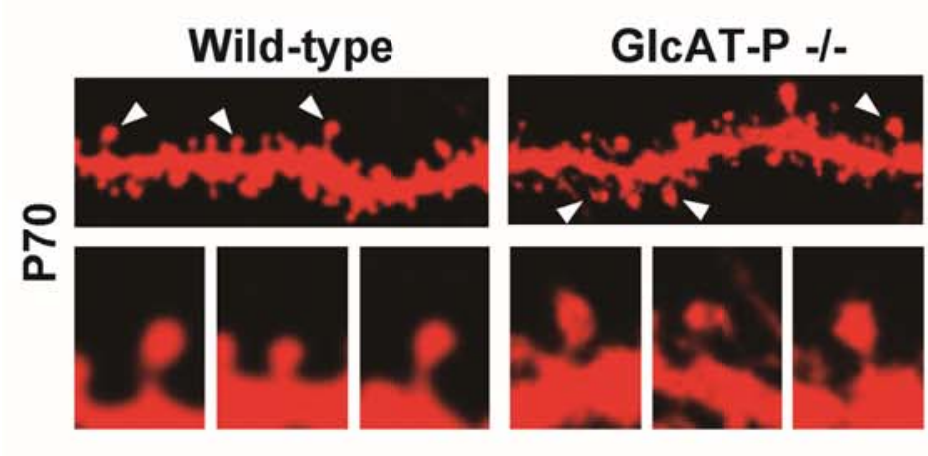

E

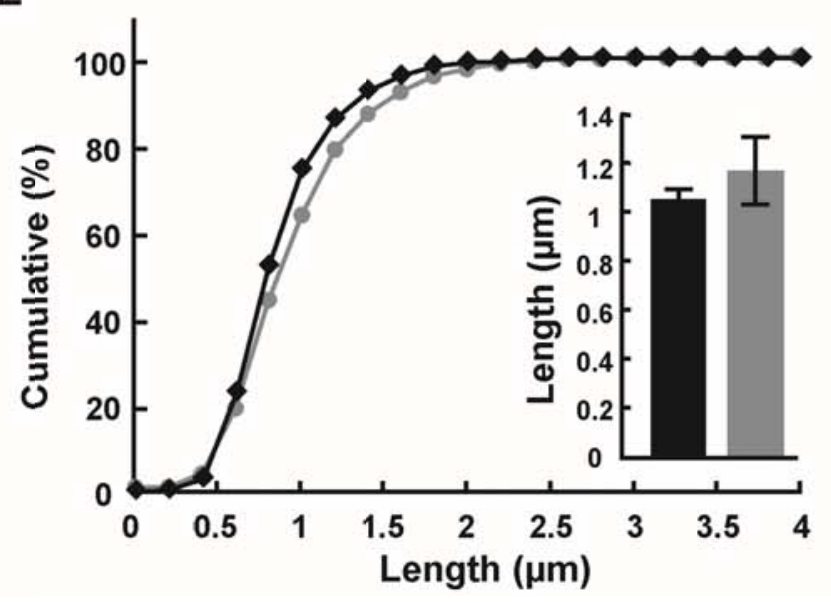

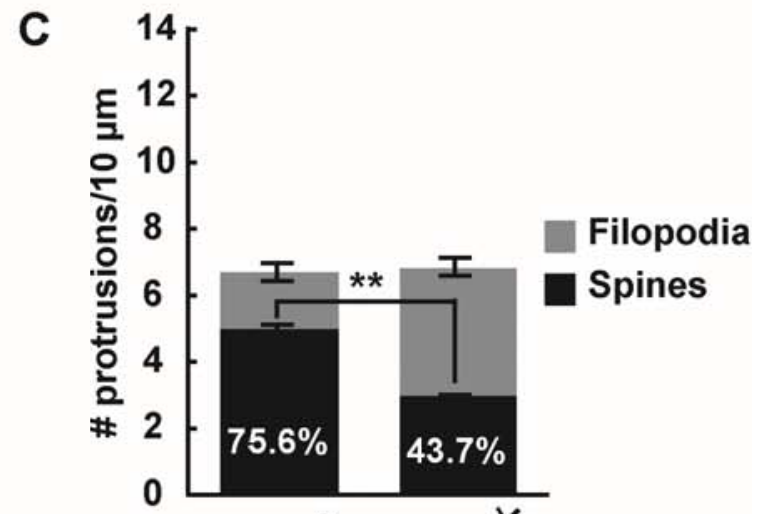
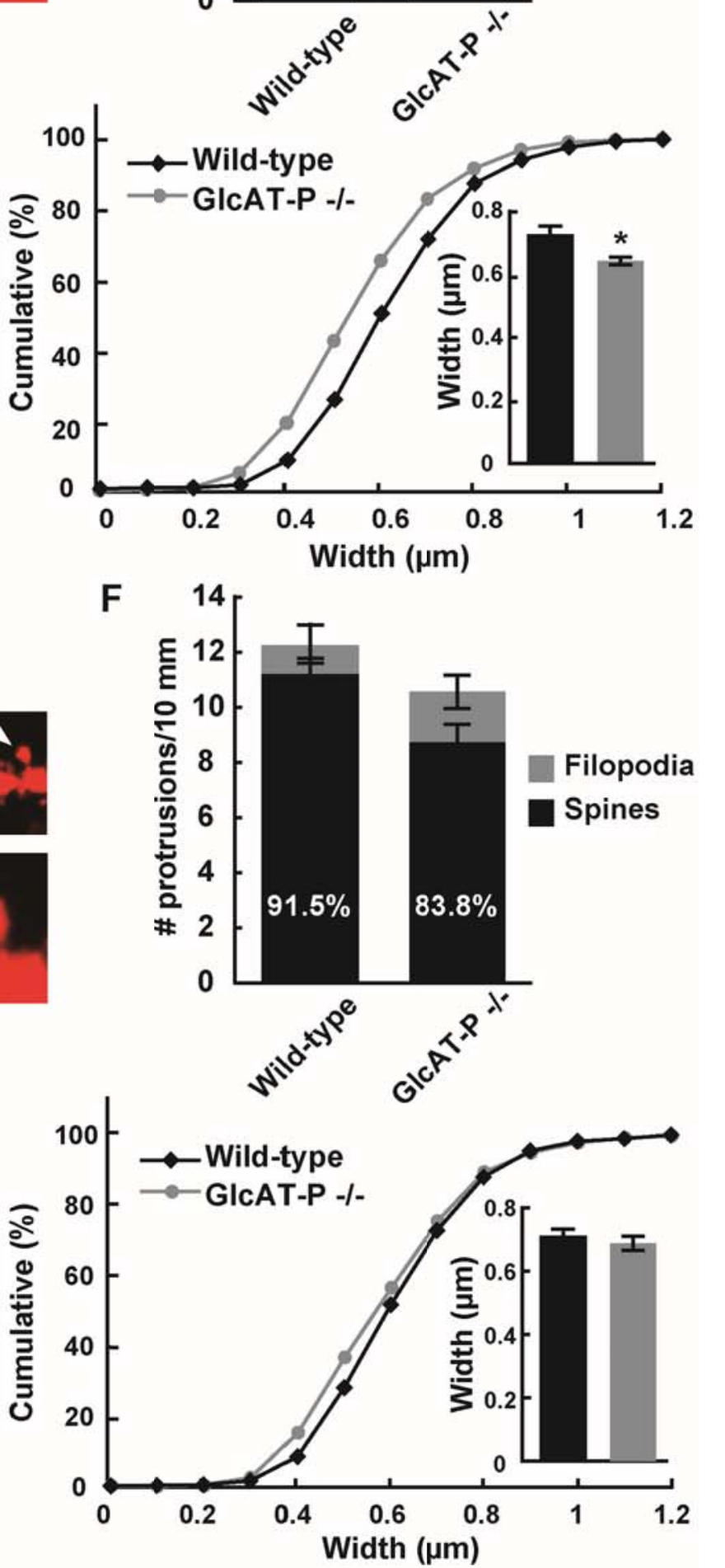
Fig. 2

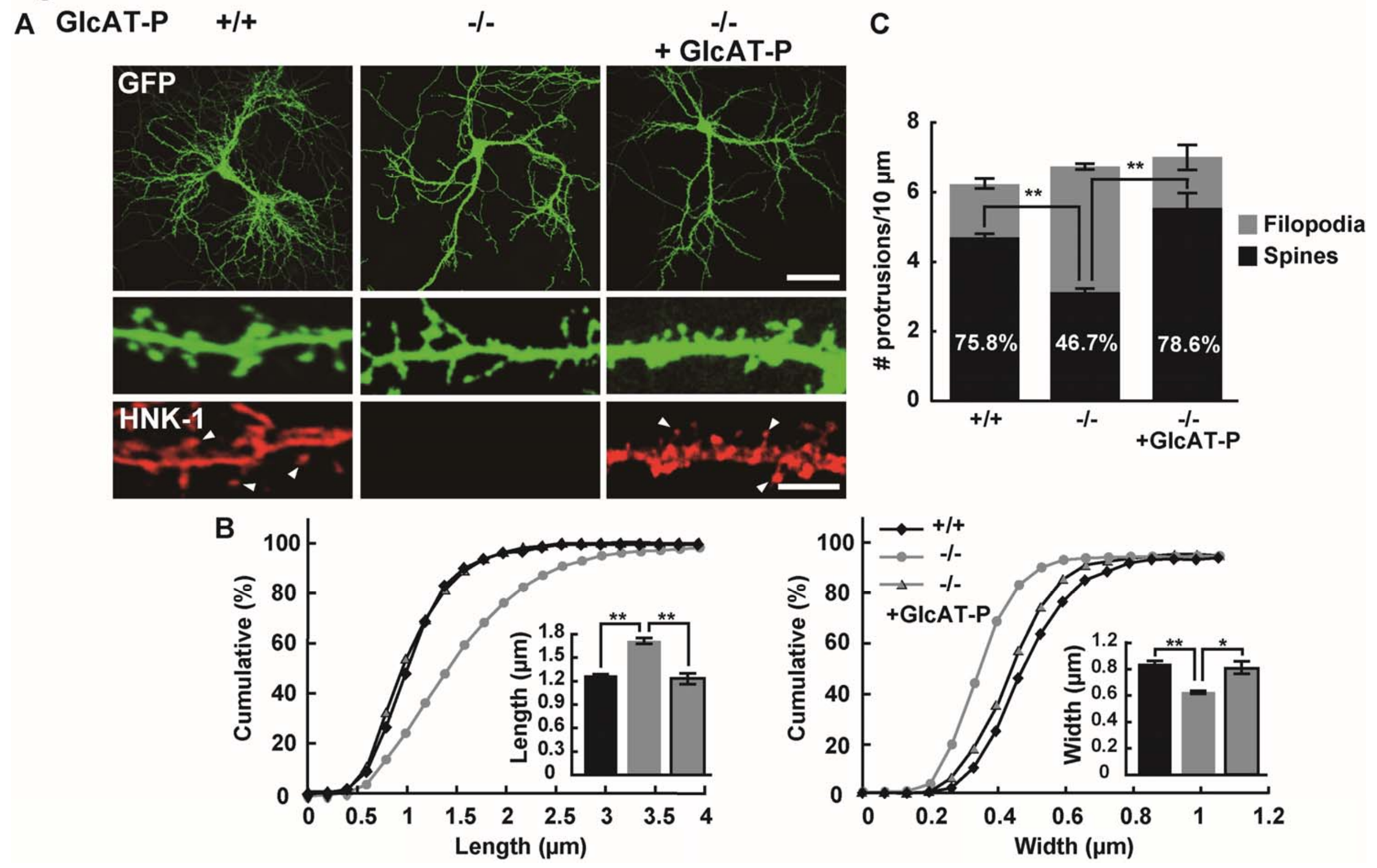


Fig. 3

A

GFP (12 DIV)

Wild-type

GICAT-P -/-

B
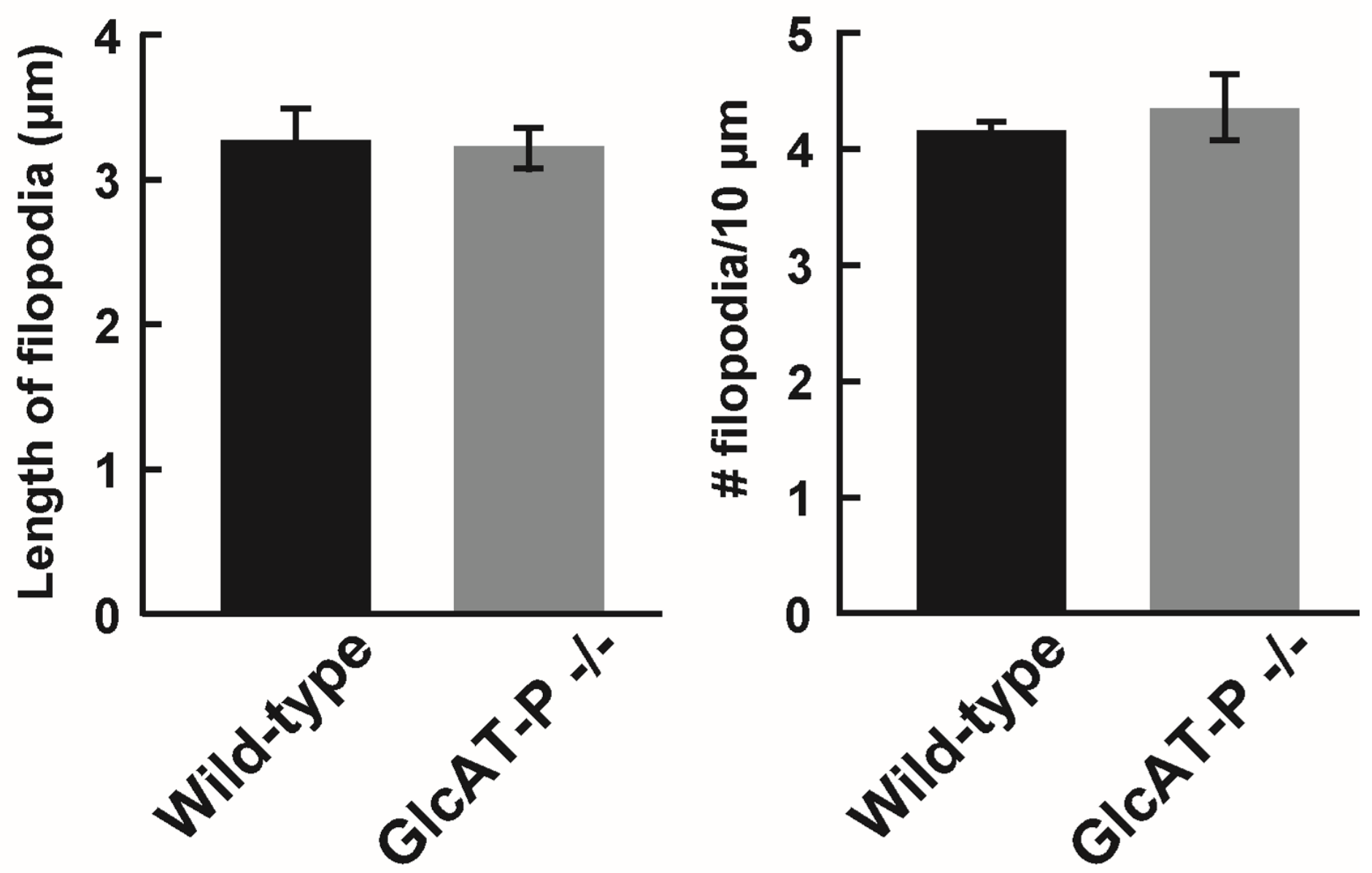
Fig. 4

A

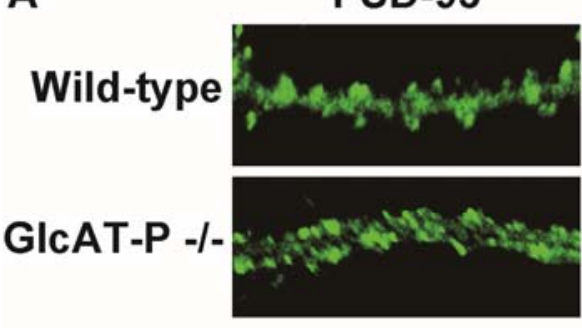

C

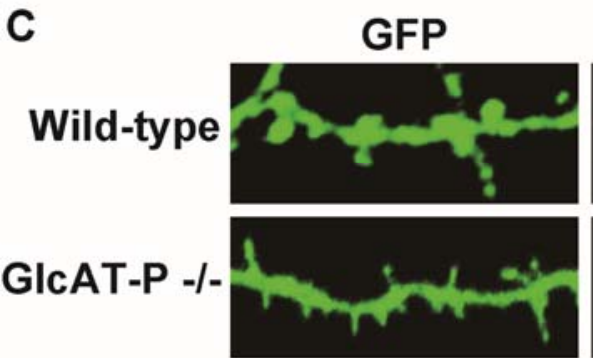

D

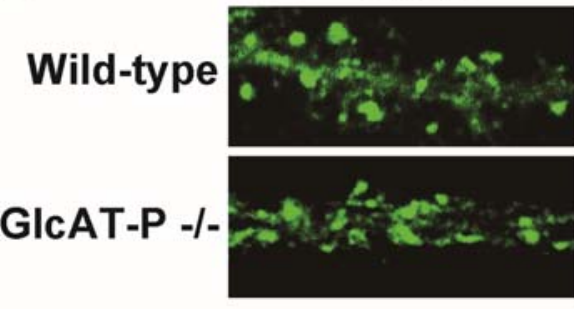

E

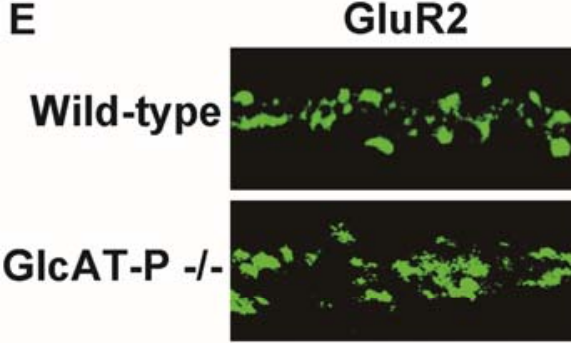

F

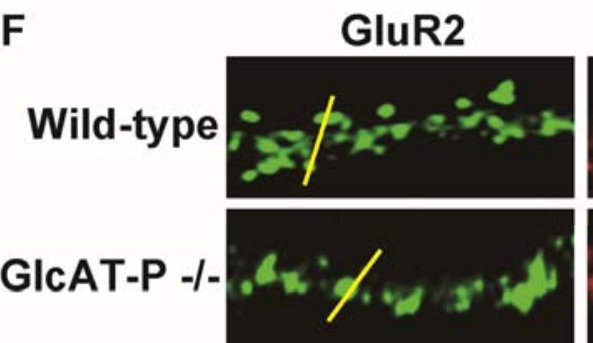

\section{Synaptophysin}
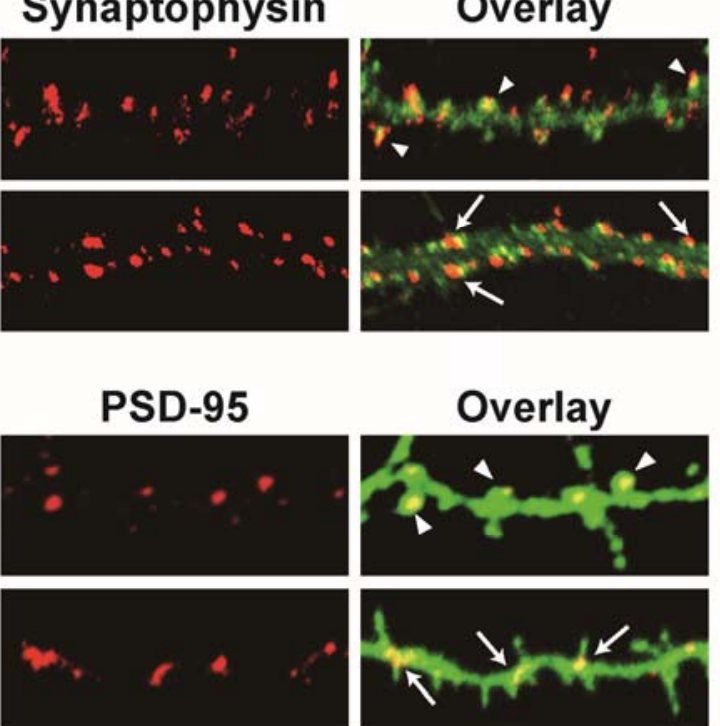

MAP-2

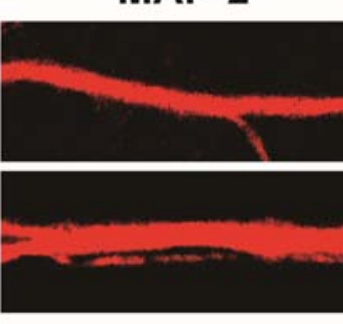

PSD-95

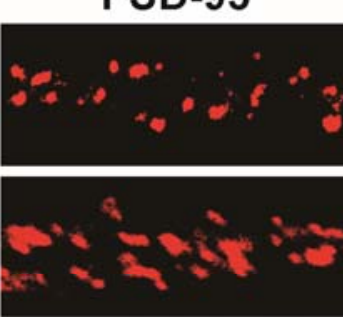

F-actin

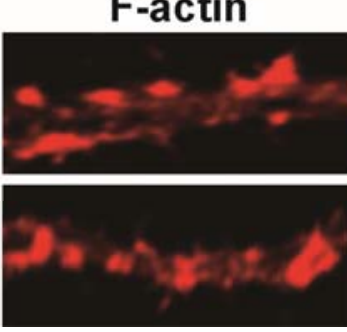

Overlay

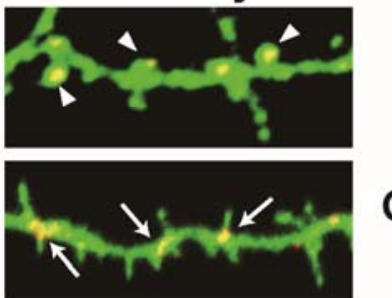

Overlay

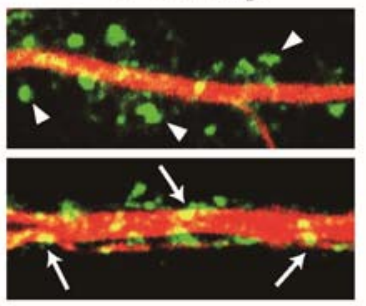

Overlay

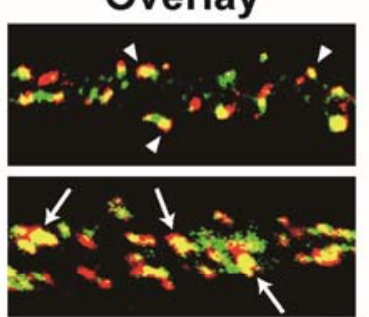

Overlay

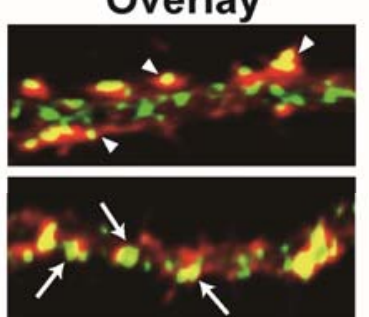

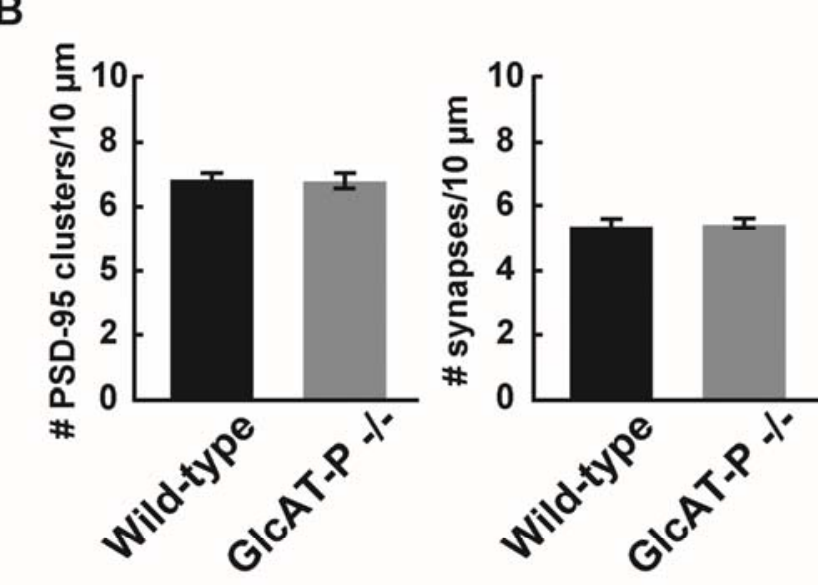

G Wild-type neuron

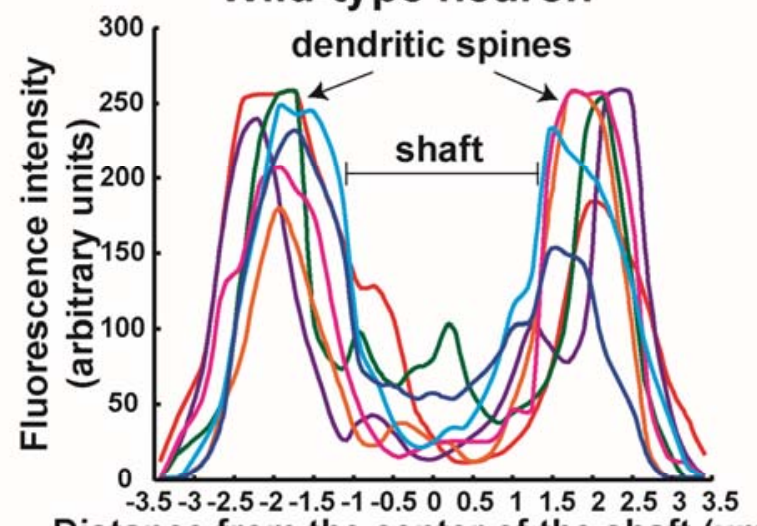
Distance from the center of the shaft $(\mu \mathrm{m})$

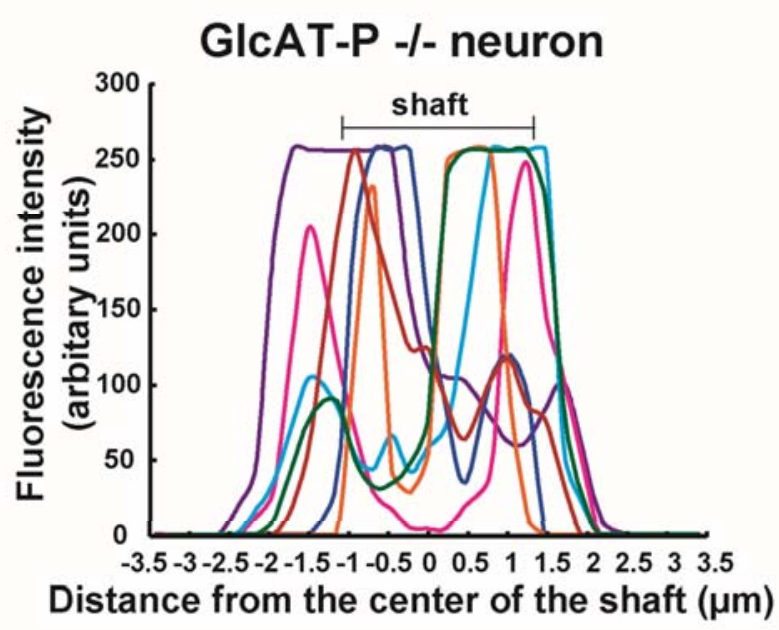


Fig. 5
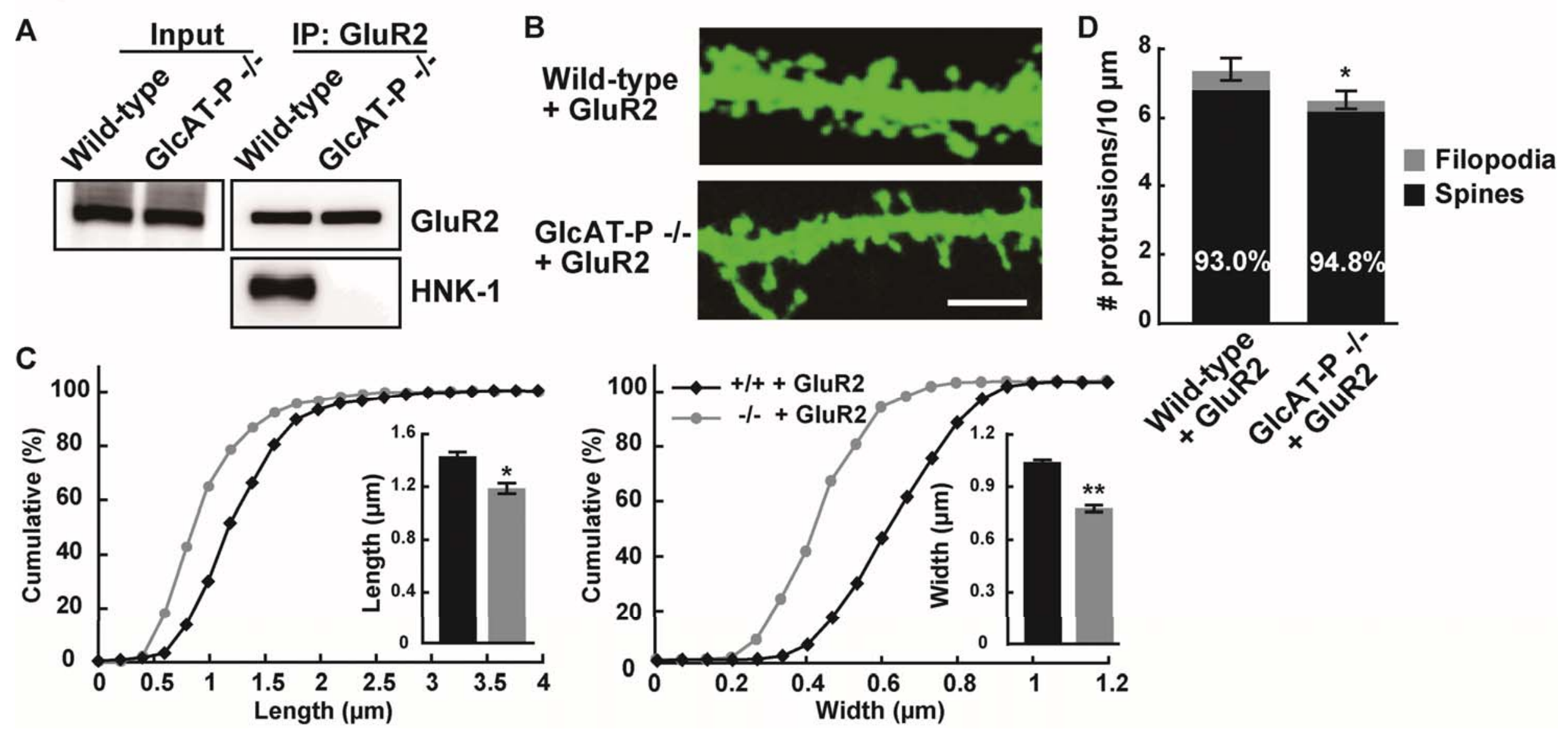
Table 1. Dendritic Protrusion Density and Size (Mean \pm SEM) in Hippocampal CA1 Neurons

\begin{tabular}{|c|c|c|c|c|c|}
\hline & \multicolumn{3}{|c|}{ Density (Number/10 um) } & \multirow{2}{*}{$\begin{array}{c}\text { Length of } \\
\text { Protrusion }(\mu \mathrm{m})\end{array}$} & \multirow{2}{*}{$\begin{array}{c}\text { Width of } \\
\text { Protrusion }(\mu \mathrm{m})\end{array}$} \\
\hline & Protrusions & Spines & Filopodia & & \\
\hline Wild-type (P14) & $6.68 \pm 0.20$ & $\begin{array}{c}5.04 \pm 0.04 \\
(75.6 \pm 2.1 \%)\end{array}$ & $\begin{array}{c}1.64 \pm 0.19 \\
(24.4 \pm 2.1 \%)\end{array}$ & $1.25 \pm 0.03$ & $0.73 \pm 0.02$ \\
\hline GlcAT-P -/- (P14) & $6.81 \pm 0.25$ & $\begin{array}{c}2.97 \pm 0.01 \\
(43.7 \pm 1.8 \%)\end{array}$ & $\begin{array}{c}3.84 \pm 0.26 \\
(56.3 \pm 1.8 \%)\end{array}$ & $1.71 \pm 0.02$ & $0.64 \pm 0.01$ \\
\hline Wild-type (Adult) & $12.29 \pm 0.68$ & $\begin{array}{l}11.23 \pm 0.50 \\
(91.5 \pm 1.0 \%)\end{array}$ & $\begin{array}{l}1.06 \pm 0.18 \\
(8.5 \pm 1.0 \%)\end{array}$ & $1.05 \pm 0.03$ & $0.71 \pm 0.02$ \\
\hline GlcAT-P -/- (Adult) & $10.46 \pm 0.57$ & $\begin{array}{c}8.72 \pm 0.59 \\
(83.8 \pm 6.8 \%)\end{array}$ & $\begin{array}{c}1.74 \pm 0.81 \\
(16.2 \pm 6.8 \%)\end{array}$ & $1.17 \pm 0.01$ & $0.69 \pm 0.02$ \\
\hline
\end{tabular}


Table 2. Dendritic Protrusion Density and Size in Cultured Hippocampal Neurons

\begin{tabular}{|c|c|c|c|c|c|}
\hline & \multicolumn{3}{|c|}{ Density (Number/10 $\mu \mathrm{m}$ ) } & \multirow{2}{*}{$\begin{array}{c}\text { Length of } \\
\text { Protrusion }(\mu \mathrm{m})\end{array}$} & \multirow{2}{*}{$\begin{array}{c}\text { Width of } \\
\text { Protrusion }(\mu \mathrm{m})\end{array}$} \\
\hline & Protrusions & Spines & Filopodia & & \\
\hline Wild-type (WT) 18 DIV & $6.23 \pm 0.11$ & $\begin{array}{c}4.71 \pm 0.09 \\
(75.8 \pm 1.5 \%)\end{array}$ & $\begin{array}{c}1.52 \pm 0.11 \\
(24.2 \pm 1.5 \%)\end{array}$ & $1.28 \pm 0.01$ & $0.84 \pm 0.02$ \\
\hline GIcAT-P -I- (KO) 18 DIV & $6.72 \pm 0.04$ & $\begin{array}{c}3.14 \pm 0.08 \\
(46.7 \pm 1.3 \%)\end{array}$ & $\begin{array}{c}3.58 \pm 0.10 \\
(53.3 \pm 1.3 \%)\end{array}$ & $1.71 \pm 0.04$ & $0.63 \pm 0.01$ \\
\hline $\mathrm{KO}+\mathrm{GlcAT}-\mathrm{P}$ & $6.99 \pm 0.37$ & $\begin{array}{c}5.52 \pm 0.46 \\
(78.6 \pm 2.2 \%)\end{array}$ & $\begin{array}{c}1.47 \pm 0.18 \\
(21.4 \pm 2.2 \%)\end{array}$ & $1.25 \pm 0.05$ & $0.77 \pm 0.01$ \\
\hline WT 12 DIV & $4.14 \pm 0.06$ & - & - & $3.23 \pm 0.22$ & - \\
\hline KO 12 DIV & $4.35 \pm 0.27$ & - & - & $3.20 \pm 0.12$ & - \\
\hline WT + GluR2 & $7.38 \pm 0.19$ & $\begin{array}{c}6.86 \pm 0.17 \\
(93.0 \pm 1.3 \%)\end{array}$ & $\begin{array}{l}0.52 \pm 0.10 \\
(7.0 \pm 1.3 \%)\end{array}$ & $1.43 \pm 0.03$ & $1.04 \pm 0.01$ \\
\hline $\mathrm{KO}+$ GluR2 & $6.50 \pm 0.21$ & $\begin{array}{c}6.16 \pm 0.13 \\
(94.8 \pm 1.1 \%)\end{array}$ & $\begin{array}{l}0.34 \pm 0.08 \\
(5.2 \pm 1.1 \%)\end{array}$ & $1.18 \pm 0.03$ & $0.78 \pm 0.02$ \\
\hline
\end{tabular}


Supplementary Fig. 1 The Golgi staining of CA1 pyramidal neurons in hippocampal slices from P14 wild-type and GlcAT-P-deficient (GlcAT-P -/-) mice. Arrowheads indicate mashroom-like mature spines, and arrows indicate filopodia. Scale bar: $10 \mu \mathrm{m}$. 


\section{Supplementary Fig. 1}

\section{Wild-type}
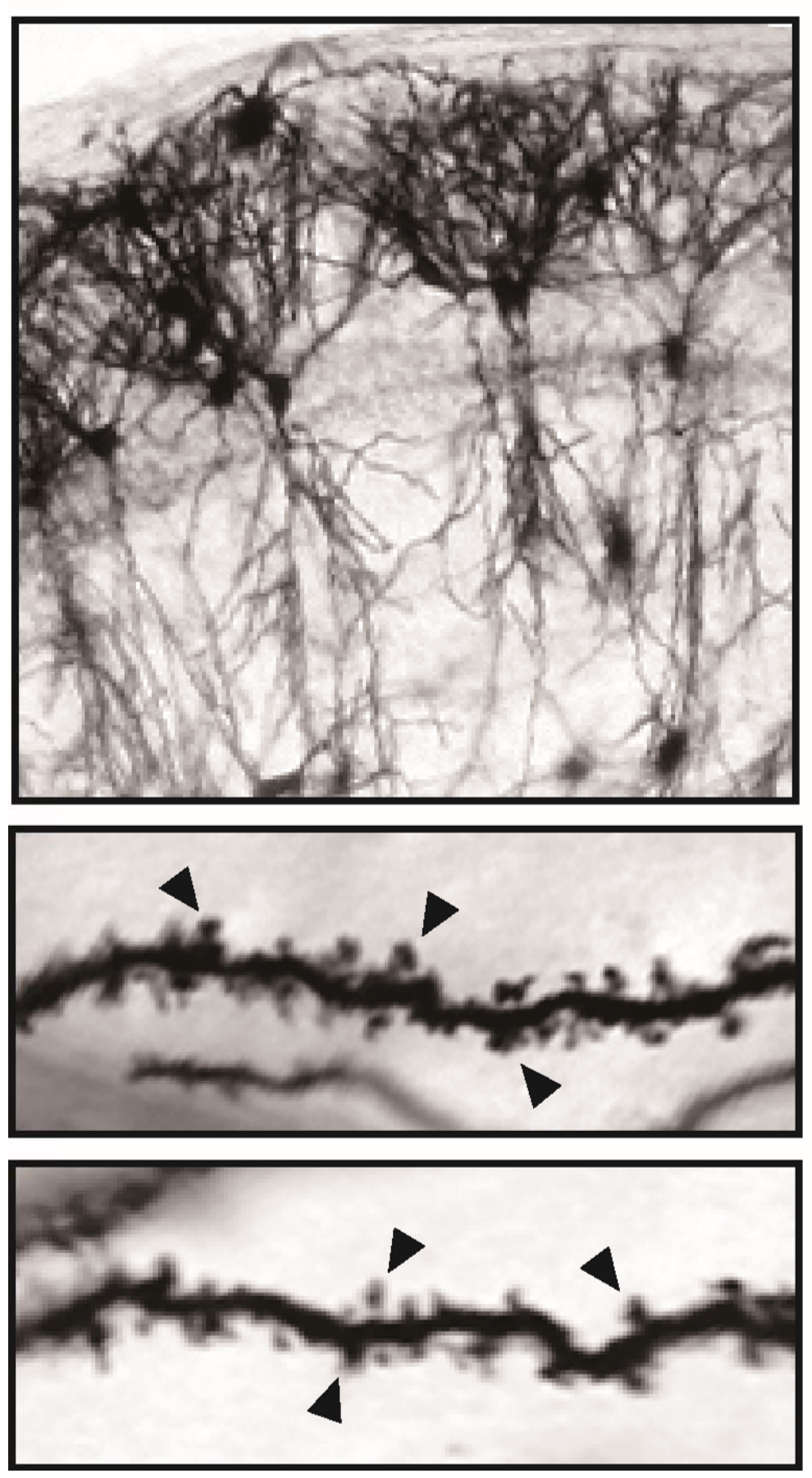

GICAT-P -/-
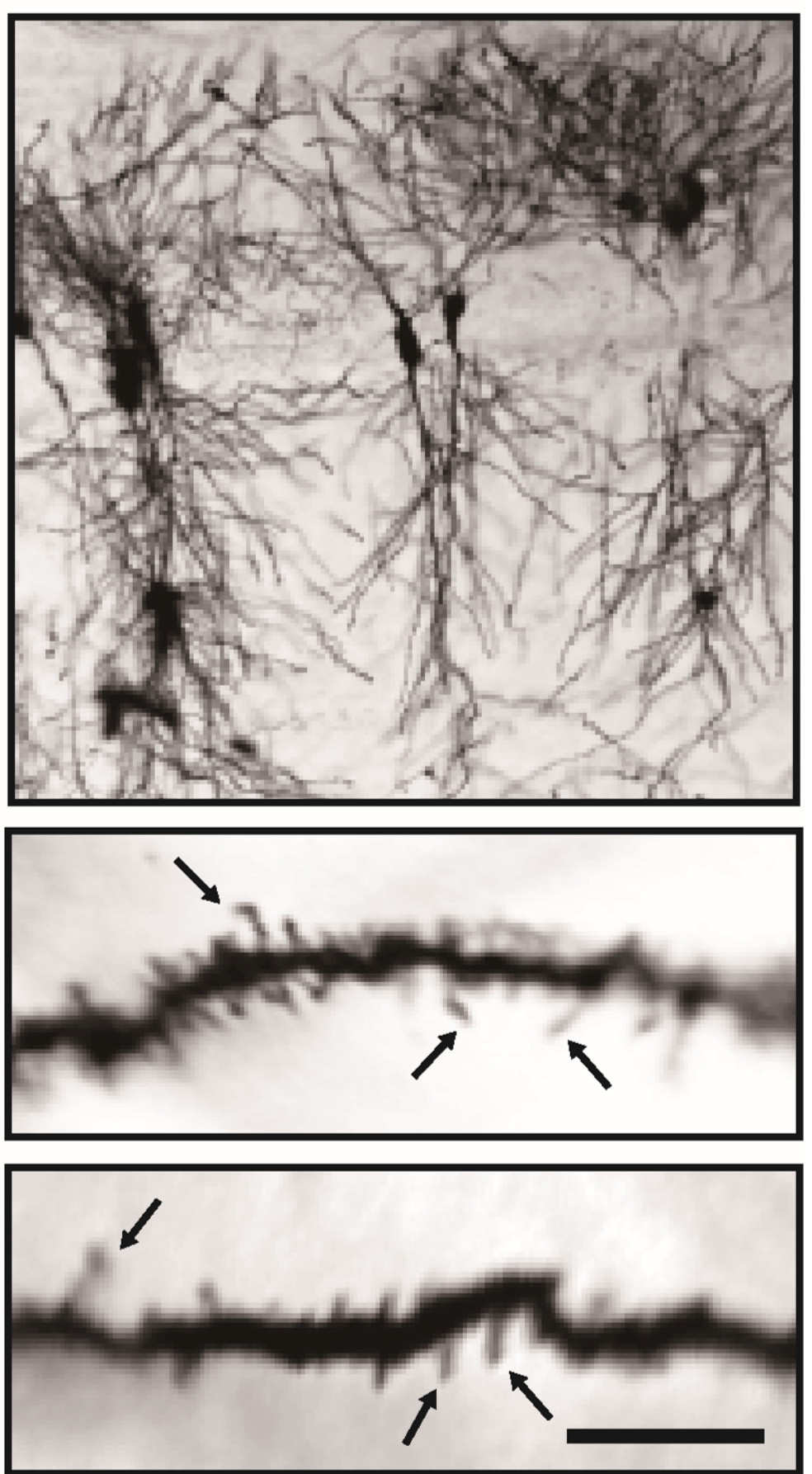